\title{
Capturing the life cycle of false hair products to identify opportunities for remanufacture
}

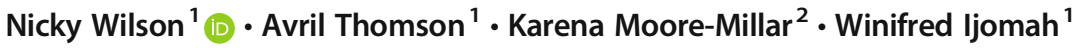

Received: 4 January 2018 / Accepted: 29 January 2019 / Published online: 11 February 2019

(C) The Author(s) 2019

\begin{abstract}
The false hair industry represents a case of growing demand and depleting natural resources, in addition to a significant environmental impact of synthetic alternatives. Despite the growth of the false hair industry, there is a lack of research to date regarding the complete life cycle of false hair products. False hair products currently follow a linear life cycle with a cradle-tograve flow of materials, making it essential that consideration is given to how such products are produced, used and disposed of. To reduce the strain on the supply of raw materials, limit the environmental impact of synthetic materials and ensure end users receive quality products at a reasonable price, there is a need to transform the current cradle-to-grave life cycle of false hair products. This research aims to capture the life cycle of false hair products and identify opportunities to sustainably capture waste within that life cycle. The study involved desktop research, an extensive user survey, manufacturer survey, an overview of the medical demand for false hair products and interviews with wig banks to capture for the first time the life cycle of false hair products. Recycling, reconditioning and remanufacture of waste materials are identified as mechanisms to reduce waste of false hair products within the UK industry, with potential for this research to impact on an international scale by reducing the global demand for natural raw materials and limiting the environmental impact of synthetic fibres.
\end{abstract}

Keywords Remanufacture $\cdot$ Circular economy $\cdot$ False hair products $\cdot$ Life cycle analysis $\cdot$ Human hair

\section{Introduction}

Hair is often associated with an individual's identity [17] with many choosing to supplement what they have or replace what they have lost. False hair products (FHPs) are defined within this paper as any product that adds to, or replaces, a person's existing hair. This includes a

Nicky Wilson

nicky.wilson.90@outlook.com

1 Department of Design, Manufacture and Engineering Management, University of Strathclyde,

Glasgow G1 1XJ, Scotland

2 Kittiwig Ltd (SC542620), 272 Bath Street, Glasgow G2 4JR, Scotland 
range of products such as full and partial wigs, weaves, toupees, toppers, extensions, eyelashes and eyebrows, all of which will be collectively referred to within this paper as FHPs. FHPs can be made from human hair or synthetic materials [17], which have differing market values based on their availability, quality and lifespan. The false hair industry is expanding globally [10]. However, the availability of human hair is decreasing [20]. Synthetic materials for FHPs are more readily available, but lack the quality of their human hair counterparts. The increasing global production of polymers (used to make synthetic FHPs) results in large amounts of waste material and associated environmental problems [4].

The false hair industry represents a case of growing demand and depleting natural resources, in addition to a significant environmental impact of synthetic alternatives, making it essential that consideration is given to how these products are produced, used and disposed of. Much work has been completed into the use of FHPs in the context of those with medical hair loss, focusing on psychology, quality of life and coping mechanisms, etc. However, previous work predominantly concentrates on the user themselves - there is little written about the FHPs themselves, consideration of the cosmetic false hair market (those with no hair loss), the practical implications of material selection of FHPs including their environmental impact and the effects of disposal of FHPs.

The lack of research available regarding the complete life cycle of FHPs presents an opportunity to explore the potential to reduce and reuse waste within this process. This paper fills the gap not addressed by previous research by taking a holistic view of the life cycle of FHPs and investigating the potential to extend the current life cycle of these products. Remanufacturing, reconditioning and recycling are widely recognised as critical strategies that can reduce waste [18] and create a circular economy (CE). This research aims to capture for the first time the life cycle of existing FHPs (including production, procurement, use and disposal) and to identify opportunities to sustainably capture and reuse waste within the current life cycle of these products. To address this aim, this paper will answer the following research questions:

1. What is the current life cycle of FHPs?

2. How can the demand on natural hair resources be reduced?

3. How can the environmental impact of synthetic FHP fibres be minimised?

\section{Overview of the false hair industry}

False hair products (FHPs) are made from human hair, synthetic fibres or a combination of both. Both the reducing supply of human hair and the growing environmental impact of synthetic fibres due to demand, are central to the need to address waste and disposal within the FHP lifecycle. This section provides an overview of both human hair and synthetic fibres used in the production of FHPs. It is noted that in some cases, wigs can also be made from animal hair - yak hair is often used to achieve a grey colour.

Human hair falls into three categories (African, Asian and Caucasian) with the biological composition of the hair being the same regardless of ethnicity [2]. It has many unique properties including slow degradation rate, high tensile strength, thermal insulation and its unique interaction with water and oils, leading to its many diverse uses, including as a building material, rope, for oil-water separation and fertilizer [9]. While large quantities of human hair used in FHPs are collected in India through the religious process called tonsuring [15], the 
collection of human hair is a global process. Human hair is widely acknowledged as the best material for preparing a wig, with Indian hair known for its high quality. However, human hair grows at a rate of $1 \mathrm{~cm}$ per month [2], therefore takes time to grow and collect - only hair of four inches or longer is suitable for use in wigs. Hair of less than four inches is referred to as "clippings" and is not currently suitable for use in the production of wigs due to manufacturing processes, where some length in the hair fibres is lost in the attachment process. These clippings are more commonly used in fertilisers and filtration products. Human hair is utilised on a large scale and traded internationally within the false hair industry [9], but is becoming increasingly difficult to acquire [27], with reports that its value is rising as women become more fashion conscious and do not want to give up their hair - "the gap between the length of time taken to grow hair and the rapidity with which extensions and wigs are consumed creates a permanent sense of tension in the market" [20]. Once the hair is collected, it is sold for millions of dollars to the false hair market [15] - the sale of tonsured hair generates $£ 20$ million a year for the Tirumala temple in India alone [20]. Human hair is then exported to countries such as China where it is manufactured into FHPs.

While human hair is acknowledged as the best material for making FHPs, synthetic materials are often cheaper and easier to source. These fibres are available in a greater range of lengths due to their production from filaments made from one continuous tow. The types of fibres used in synthetic wigs have changed considerably over the past few decades in order to better resemble human hair [6]. Materials used in synthetic wigs include (but are not limited to) polyvinyl chloride (PVC), polyethylene terephthalate (PET) and polyacrylonitrile (PAN) [27], produced through the process of fibre spinning [7]. China, Japan and Korea are global leaders in the production of synthetic hair fibres, which are then distributed to a global market. These materials are cheaper and quicker to produce than their human hair equivalent but disadvantages include an unnatural look (due to uniform shine) and feel, heat related issues (including exposure to and the ability to dissipate heat) and breakage of the users remaining hair due to friction between the hair and cap [3].

The false hair industry is growing globally, with an annual estimated turnover of $£ 6.2$ billion (around $\$ 8.3$ billion) in the UK alone [10]. Estimates indicate the UK imported $\$ 773,000$ worth of human hair year in 2016 , with global imports of human hair totalling $\$ 65.3$ million [21]. Stock synthetic wigs, produced from machined wefts form the cheaper end of the market and can cost between $\$ 30$ and $\$ 300$ [17]. Hand-tied net foundations, made from synthetic or human hair, cost between $\$ 300$ and $\$ 1000$ and have a more natural look [6]. High end wigs made from human hair can cost upwards of \$2000 [17]. Inexpensive synthetic wigs worn daily need to be replaced every 3-6 months, while high quality human hair wigs can last 3-4 years [17]. While the cosmetic market for FHPs continues to grow in demand, there is also a strong case for ensuring such FHPs remain affordable for those whom such products are a necessity. There is a large market presented by those with medical hair loss (alopecia). Research indicates that hair loss can negatively affect both emotional health and quality of life [8]. For this group of users, the use of FHPs allows those with alopecia to conceal their hair loss [25], [16] and gain self-confidence and social acceptance [3].

As the current market for FHPs continues to grow, there is an increasing demand on the supply of human hair - human hair is becoming harder to source [20], while synthetic materials are readily available and disposed of, contributing to a significant environmental footprint. To ensure the FHP market is sustainable, it is timely to consider alternatives to current methods of product disposal to extend the product life cycle. It is in the interest of the 
global false hair industry that the supply of FHPs continues to meet user demands, while minimising environmental impact.

\section{The need to reduce waste in the FHP industry}

FHPs currently follow a linear life cycle with a cradle-to-grave flow of materials. Human hair waste takes several years to decompose to its constituent elements of namely carbon, nitrogen and sulphur [9]. It is slow to break down and blocks drainage systems and produces foul odours [9]. Synthetic materials likewise occupy large volumes within landfill disposal but do not decompose over time [24], while alternatives such as burning releases highly toxic chemicals which can impact human health [5]. It is estimated that around a third of all plastic waste is designed to be non-reusable and discarded after 12 months [13], reflective of the design of synthetic FHPs. There is a growing importance on the environmental performance of products for sustainable manufacturing [18] with recommendations made [9] to develop new systems which utilise waste hair material as a resource. The high volumes of waste currently produced by society presents the opportunity for circular principles to better utilise resources to improve the current linear life cycle of many products [14]. Within this research, opportunities for recycling, reconditioning and remanufacture of FHPs are considered to reduce the waste produced by the false hair industry and extend the life cycle of these products.

Remanufactured products can be referred to as refurbished, rebuild, recertified, etc. [1] which will be collectively termed "remanufactured" within this paper. Remanufacturing is a process used to bring products to a "like new" functional state with a warranty to match [12]. During the remanufacturing process, a substantial proportion of the resource is incorporated into the new product, reducing the amount of waste material deposited in landfill. Additional benefits to remanufacturing include discounts on remanufactured products [1]. Remanufacture differs from recycling (recovering materials for reuse in their original or new purpose) and reconditioning (returning a product to a satisfactory working condition that may be inferior to the original specification) [19]. However, there are issues with remanufactured products that must be addressed within this study. Recent research to investigate user perceptions of remanufactured products [1] found that many consumers believe that a product becomes dirty or contaminated due to prior ownership of the product. FHPs are highly personal products, which are often fitted to an individual's head and cut and styled to their own preference. User perception towards the remanufacture, reconditioning and recycling of such products is critical to ensure there is a demand for such products and that value can be created in extending the life cycle of these products.

\section{Current use of waste FHP materials}

There is limited literature available that discusses the use of waste materials within the FHP industry. Gupta [9] discusses alternative uses of general human hair waste but does not capture the life cycle of hair that is used in the false hair industry, nor does the paper consider synthetic fibre alternatives to human hair. The paper presents an overview of the disposal of human hair waste, which are categorised into the following three types, as illustrated in Fig. 1:

- $\quad$ Type 1: Hair waste is incorporated back into the natural biological cycle. Only hair that falls into the Type 1 category does not accumulate in waste streams as the hair 
decomposes during processing or use. Uses of Type 1 waste include agriculture and the extraction of amino acids.

- $\quad$ Type 2: Waste is recycled or reused for the same or other applications as shown in Fig. 1. The extent to which the product can be recycled depends on other materials contained within the product. Increasing Type 2 uses of waste within the false hair industry is the focus of this research.

- Type 3: Uses of hair do not decay the hair or leave it safe for recycling, resulting in waste that difficult to dispose of.

There is a gap presented in the literature as the current life cycle of FHPs and the disposal of both human hair and synthetic fibres used in FHPs are not discussed. This research will address this gap by investigating opportunities for capturing both human hair and synthetic material waste within the current life cycle of FHPs. This research will focus on Type 2 reuses (as shown in Fig. 1) of both human and synthetic FHPs to extend the life cycle of these products, reduce the demand for raw materials and reduce the waste produced within the false hair industry. It is noted that Type 2 reuse of materials does not prevent materials entering the waste streams eventually (only Type 1 will achieve this). However, it will increase the availability of both human hair and synthetic materials and extend the life cycle of FHPs, therefore reducing the overall quantity of FHPs disposed of. The potential to recondition, recycle and remanufacture FHPs requires further research to establish a need amongst users for such products and at what point a remanufactured or reconditioned product becomes more desirable than buying new. These factors will be considered within this research to ensure outcomes are practical and will address user demands.

\section{Research approach}

The life cycle of FHPs was split into four key stages: 1) global sourcing and manufacture of FHPs, 2) UK imports and exports of related products (including manufacturers and suppliers in the UK), 3) product use and 4) disposal, as shown in Fig. 2.

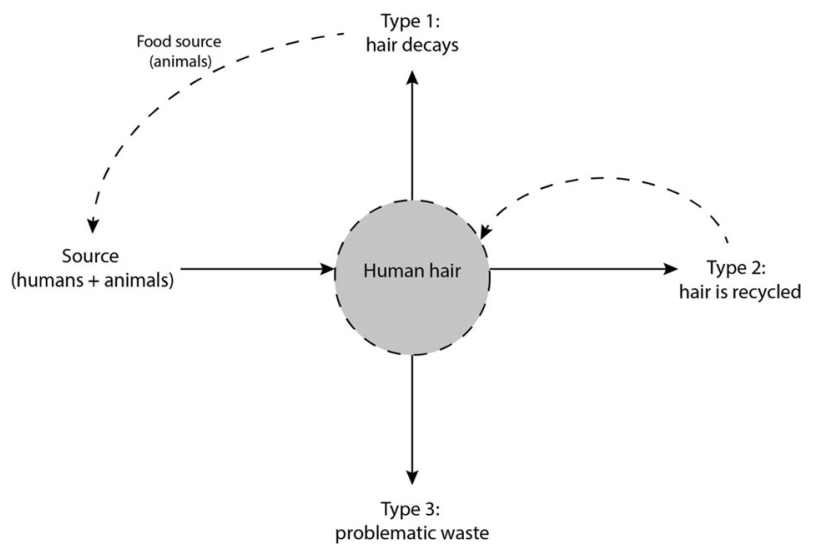

Fig. 1 Reuse areas for human hair waste. Adapted from Gupta [9] 


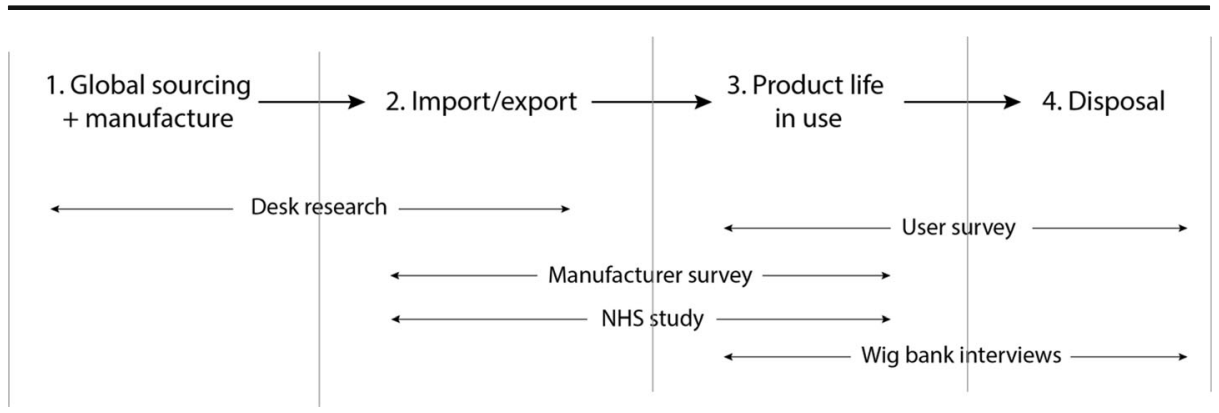

Fig. 2 Research approach

To capture information for Stages 1 and 2 of the life cycle of existing FHPs, initial extensive desk research was undertaken and included a literature review, internet search and informal discussions with suppliers, sellers and manufacturers of FHPs. The focus of the research was on the UK market. However, it is acknowledged that the hair market is a global one, with the origins of FHPs existing out with the UK. Given the lack of data available in relation to the false hair industry, data of the global market was utilised where required - this is indicated where used. Due to a lack of data from peer reviewed sources, information was gained from a variety of industry reports and articles which were cross referenced with other sources to ensure confidence in findings.

To gain a detailed understanding of product life in use and disposal (Stages 3 and 4), an extensive user survey and wig bank interviews were carried out, in addition to a study with the National Health Service in the UK (NHS) to identify the use of FHPs by those with hair loss.

For the purpose of the user study, three user groups were identified:

1. Long term hair loss - those with long term condition resulting in her loss where the hair will never grow back.

2. Short term hair loss - those who experience temporary hair loss, (i.e. as a result of undergoing chemo therapy).

3. No hair loss - none or limited hair thinning, where false hair products are used to enhance, extend or maintain the existing hair.

These high level user type categories can be broken down further as shown in Fig. 3.

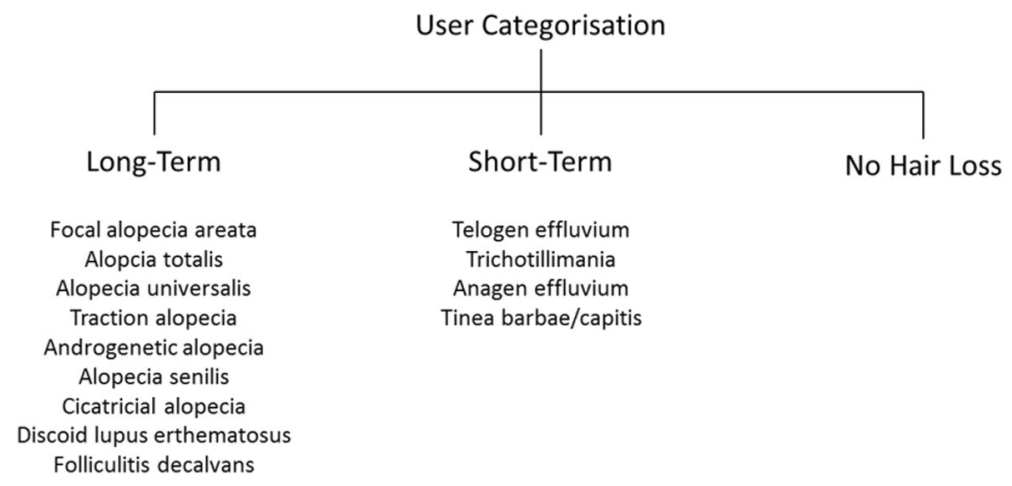

Fig. 3 Breakdown of user categories 
To understand product life in use and disposal, a survey was created for each of the three user groups (long term hair loss, short term hair loss and no hair loss), with questions covering the following three areas:

1. Purchasing of a false hair product.

2. Use and maintenance of a false hair product

3. Disposal of a false hair product

The user surveys generated 231 respondents with long term hair loss, 40 with short term hair loss and 67 with no hair loss. Both the long and short term hair loss surveys were completed by users in the UK, while the survey for those with no hair loss was completed internationally. 54 questions were asked in total with each user group asked the same set of questions - wording of questions was altered to suit the target user group. Users were questioned on the type of FHP worn, frequency of purchasing FHPs, methods of FHP disposal and attitudes towards sustainable and ethical sourcing and manufacture of FHPs. Qualitative responses were analysed using a general inductive approach [23] with key themes identified and the process validated by two researchers.

To provide a greater understanding of the size of the medical market for FHPs in the UK, a study was conducted to identify the number of people with medical hair loss and the number of FHPs prescribed annually through the NHS. Freedom of Information requests were made to all NHS regions in the UK and requested information including total number of people experiencing hair loss, a breakdown of different types of hair loss, the number of people experiencing hair loss as a result of medical treatment and the number of FHPs prescribed annually by the NHS.

A further survey was distributed to wig suppliers and manufacturers based in the UK. 24 questions were asked and included types of products manufactured and sold, reasons for manufacturing/supplying, sources of greatest demand, customers and source of materials/ products. 14 suppliers and manufacturers responded.

In addition to the user survey, short semi-structured interviews were conducted with six wig banks in the UK to gain a greater understanding of current reuse and disposal of FHPs. Wig banks encourage those who no longer want their FHP (typically a full wig) to donate them to the wig bank, where the wigs is cleaned and resold at a discounted price. Interviews lasted 1015 min and asked questions including how many (and what type) of FHPs were donated to the wig bank, materials of the FHPs, condition of the FHPs, process of cleaning and treating the FHPs for reuse and methods of reuse/disposal for products that were in poor condition.

\section{Results}

This section presents the results from the desktop research, manufacturer and user surveys, NHS study and wig bank interviews that were conducted in this research. The section is structured according to the four high level stages of the FHP life cycle: global sourcing and manufacture of FHPs, UK imports and exports of related products (including manufacturers and suppliers in the UK), product use and disposal.

\section{Global sourcing and manufacture}

As identified in the literature, the majority of human hair is sourced from India, through the religious process of tonsuring [20], although China, Brazil, Peru and Eastern Europe 
are major sources of human hair. In countries such as the UK, human is donated to charities to be made into wigs for those that have lost hair for medical reasons. Hair that has been sourced from Europe is much more expensive [17] due to its colouring and lack of availability. Synthetic materials for FHPs are typically manufactured in countries including China, Japan and Korea.

The raw materials (both human hair and synthetic fibres) are sent to countries including China, Myanmar and Bangladesh for manufacturing - China is the biggest importer of human hair according to data from the Observatory of Economic Complexity [21]. With limited peer reviewed data available, market reports estimate that China increased its imports of human hair to 1.1 million $\mathrm{kg}$ in 2015. It is during the manufacturing process that human hair is chemically treated. This process involves untangling the hair by hand, bleaching and chemically treating the hair to remove the cuticles. The exact chemicals used in this process remain unknown. The finished products (both human hair and synthetic FHPs) are then exported, with countries including the United States, United Kingdom and other parts of Western Europe as major importers of FHPs. Figure 4 summarises the global trade in both human hair and synthetic FHPs.

International standards (ISO9001:2000 and ISO4001:2015) are met by some major suppliers of synthetic materials used in FHPs and relate to requirements for a quality management system in the organisation and requirements for an environmental management system for the organisation to enhance environmental performance. However, it is not apparent whether these standards are met by all major suppliers and there was no evidence found of standards in place to regulate the quality of the product or safety of the user or of any quality control relating to the sourcing or processing of human hair.

\section{UK import/export of FHPs and related materials}

On a global scale, a review of internet findings indicates that China, Indonesia and Hong Kong are the main exporters of human hair wigs, with the total export value around $\$ 1.2$ billion in 2015 [21]. Top importers of human hair wigs were the USA, Japan, UK, France and Republic of Korea, with a global import value of $\$ 98$ million [21].

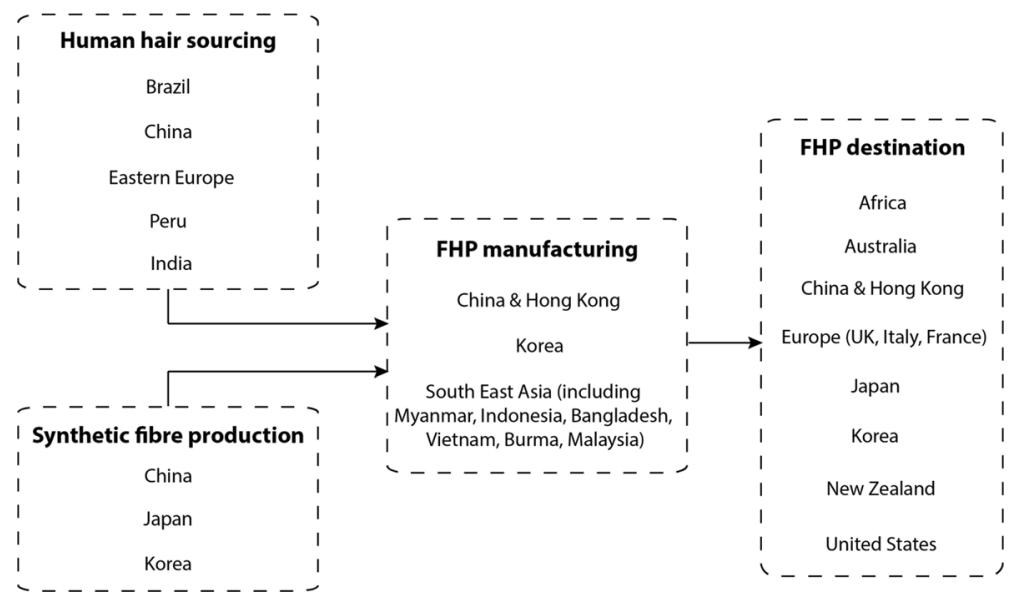

Fig. 4 Global distribution of FHP materials 
Analysis of UK imports and exports through the Observatory of Economic Complexity (OEC) [21] database identified a lack of standardisation regarding the categorisation of false hair products. The following classifications were identified as relevant to the FHP industry:

- Hair, human unworked, waste human hair

- Wigs, false beards, eyebrows, etc. of human hair

- Wigs, false beards, eyebrows, etc. of other materials

- Complete wigs of synthetic textile materials

- Fake hair

- Processed hair

- Human hair

UK imports and exports of these products are summarised in this section. There has been a rise in the amount of FHPs and related material exported from the UK since 2010, reaching a peak in 2014 as shown in Fig. 5. It is unclear why this then dropped in 2015 - potentially due to changes in legislation or categorisation of such products. However, there has been a general rise in the value of exports over this five year period. What remains unknown from the data is the quantity of individual units - this raises uncertainty over whether more products are being exported or if it is simply the value of those products that has increased. Fake hair was the highest value export over this time frame, although it is unclear exactly what products fall under this category.

UK imports also show a general increasing trend since 2010, with a significant increase in the import of fake hair and human hair products in 2012, as shown in Fig. 6. Again the case for this rise is unknown. Fake hair is again the highest value import, with fake hair, wigs made from synthetic materials and wigs made from human hair showing an increase over the time frame.

It is noted that the above data has shortcomings, regarding the definition of the categories provided by the OEC. No definitions are provided within the data source, leading to difficulties in identifying the types of materials and products included in each import and export category. For example: not all human hair waste may be utilised in the false hair industry, fake hair does not necessarily imply it replicates human hair nor that it is used for the purpose of FHPs, while processed hair may not necessarily be human. However, by examining all categories an overview of the import and export of the materials used in the false hair market in the UK is provided.

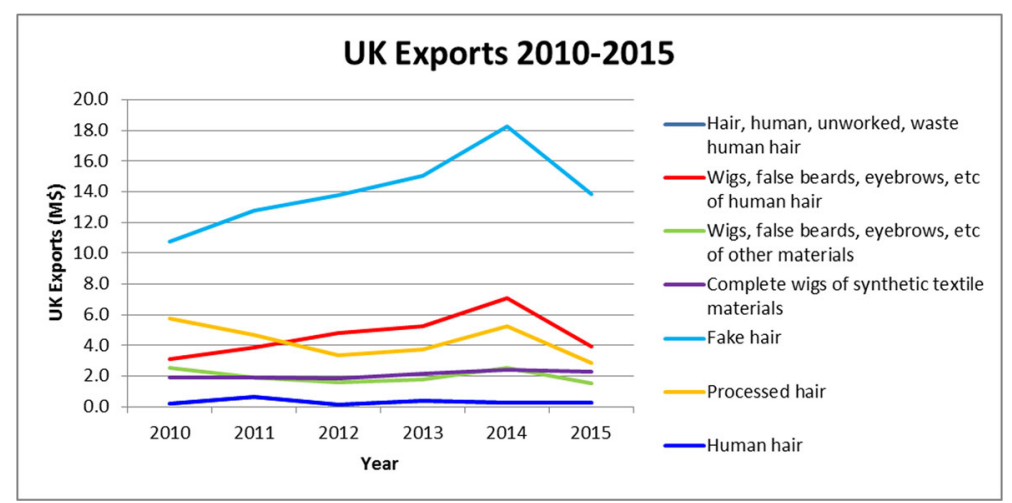

Fig. 5 UK exports of FHP materials 


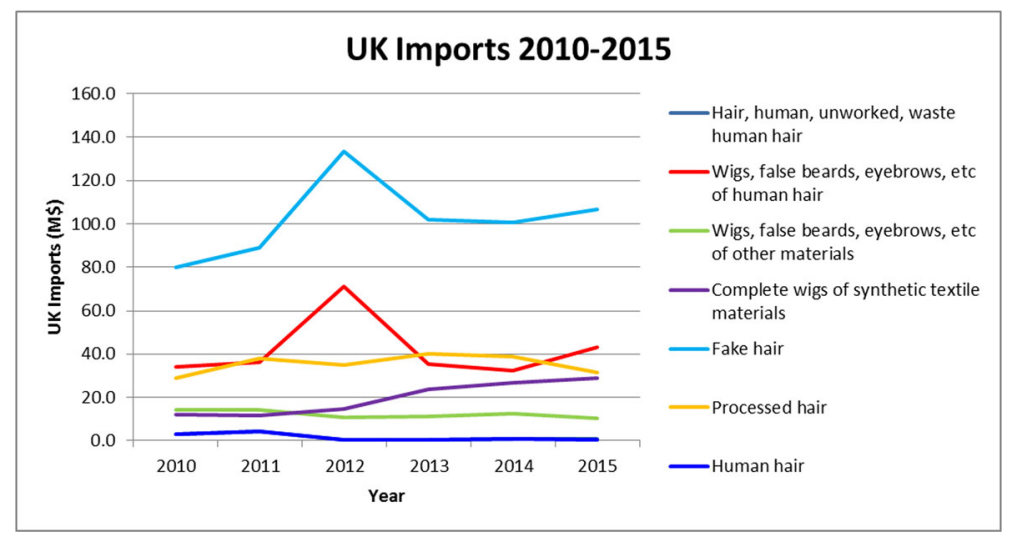

Fig. 6 UK imports of FHP materials

Additional information relating to the UK's import and export of FHPs came from charities in the UK, which provides wigs to cancer patients who have lost hair due to treatment. Informal discussions with the charity identified, since its creation in 2006, the charity has given out 5000 wigs, typically at a rate of 100 per month. The charity reported that donated hair was received in ponytails and plaits, which was sorted in terms of colour and length and air freighted to the manufacturer, categorised for export as "human hair". The finished product is returned to the UK as "hair pieces". Based on the data gathered from the OEC, it is unclear what category "hair pieces" would fall under.

Based on the import/export data for the UK, an assessment of the environmental impact of the global supply chain of FHP materials and production estimated the carbon emissions to transport manufactured FHPs from China to the UK was calculated. Using figures provided by the World Shipping Council [26], a 10,000 container capacity cargo ship emits $10 \mathrm{~g} \mathrm{CO} 2$ to carry one tonne of cargo $1 \mathrm{~km}$, it was estimated that the transport of one tonne of FHPs from Qingdao Port to Felixstowe would produce 227,040 $\mathrm{g} \mathrm{CO}_{2}$. Market reports estimate the UK imports around $1000 \mathrm{t}$ of FHP products and materials a year, resulting in $2,270,400 \mathrm{~kg} \mathrm{CO}$ annually - equivalent to the annual $\mathrm{CO}_{2}$ emissions from 400 homes in the UK [11].

In a survey to wig suppliers and manufacturers in the UK, it was found that only $17 \%$ solely sourced products from within the UK, indicating that this is very much an international industry. Companies that responded manufactured and sold a range of FHPs, with full and partial wigs, toupees and wefts the most popular. Other products included weaves, extensions, toppers and eyelashes. Full wigs were reported as the bestselling product due to high demand however, it is noted that this may be due to many respondents indicating that they were a supplier of wigs to the NHS.

\section{Use of false hair products}

This section presents the results gained from the NHS in relation to the number of patients registered with hair loss and the number of wigs provided by the NHS. Results from the user surveys are presented in relation to those using FHPs due to medical hair loss and those using FHPs with no hair loss. 


\section{NHS provision of FHPs}

Results from Freedom of Information requests to the NHS were analysed to assess the medical demand for FHPs and the product type supplied by the NHS. The provision of wigs on the NHS varies within the UK. In Scotland, alopecia patents can receive up to four synthetic wigs or one human hair wig per year from the NHS. Cancer patients who have lost their hair can receive up to two synthetic wigs per year, but cannot receive a human hair wig from the NHS [11]. In other parts of the UK, there are no nationally set limits on the number of wigs a patient can receive from the NHS, although there is nothing in place to prevent local NHS organisations from setting their own limit [22]. Unlike in Scotland, users receiving wigs provided in other parts of the UK are subject to prescription charges. Human hair wigs are not provided by the NHS in England unless the patient is allergic to the synthetic alternative.

Table 1 summarises the responses gained from the Freedom of Information request to each NHS region. Only eight regions provided data on the number of people registered with hair loss, with two providing data on wig suppliers and number of wigs provided. It was found that hair loss is often either not recorded or is contained within individual patient case files and therefore not accessible with a Freedom of Information request. As hair loss is often experienced as a result of another medical condition (i.e. cancer treatment) it is not the primary cause

Table 1 Registered hair loss in patients by NHS region

\begin{tabular}{|c|c|}
\hline NHS Regions & Response \\
\hline \multicolumn{2}{|l|}{ Scotland } \\
\hline Ayrshire + Arran & Data not centrally recorded \\
\hline Borders & Data not centrally recorded \\
\hline Dumfries & Data not centrally recorded \\
\hline Fife & Data provided \\
\hline Forth Valley & None - access to patient files needed \\
\hline Grampian & Data not centrally recorded \\
\hline Greater Glasgow & Does not hold the information \\
\hline Highland & Data not centrally recorded \\
\hline Lanarkshire & Data not centrally recorded \\
\hline Lothian & Data provided \\
\hline Orkney & None - access to patient files needed \\
\hline Shetland & None - access to patient files needed \\
\hline Tayside & Data provided \\
\hline Western Isles & Data provided \\
\hline \multicolumn{2}{|l|}{ England } \\
\hline NHS England & Data provided \\
\hline \multicolumn{2}{|l|}{ Northern Ireland } \\
\hline Belfast & Does not hold the information \\
\hline Northern & Hair loss not coded for \\
\hline Southern & Data provided \\
\hline Western & Data not collected \\
\hline BSO N.Ire & Data provided \\
\hline \multicolumn{2}{|l|}{ Wales } \\
\hline Abertawe & Data not collected \\
\hline Aneurin Bevan & Data provided \\
\hline Betsi Cadwaladr & Data not collected \\
\hline \multicolumn{2}{|l|}{ Cardiff } \\
\hline Cwm Taf & No data provided - although numbers low \\
\hline Hywel Dda & None - access to patient files needed \\
\hline Powys & Data not centrally recorded \\
\hline
\end{tabular}


for the patient to be admitted. However, this does not address why there is no record of those with long term hair loss available from the NHS.

The lack of data regarding the number of patients with medical hair loss is surprising, but further highlights the lack of data available in this field. NHS Scotland reported providing 13,328 wigs in 2016, while Northern Ireland reported 2991 wigs fitted for the year 2013. The NHS in England and Wales were unable to provide the total number of wigs provided by the NHS. The lack of data relating to those with long term hair loss and those with hair loss as a result of chemotherapy is concerning and makes it difficult to estimate the size of this market.

\section{User survey - Long and short term hair loss}

To gain a more detailed understanding of the types of FHPs used by those with hair loss, a user survey was conducted with two user groups with hair loss: those with long term hair loss and those with short term hair loss. 231 people with long term hair loss and 40 with short term hair loss responded.

Full wigs were the most popular FHP, used by $90 \%$ of those with long term hair loss and $75 \%$ of those with short term hair loss. Synthetic fibres were the most common material, used by $64 \%$ with long term hair loss and $59 \%$ of those with short term hair loss. The findings of product type and material are summarised in Fig. 7. Users reported that maintaining a natural

What type of false hair product do you use?

Long term hair loss

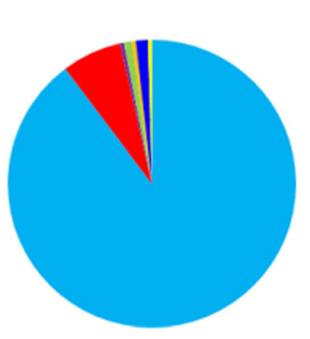

a Full wig

- Partial wig

none

= Hair extensions

= Pony tail

- Hair integration

system
Headscarf
Short term hair loss

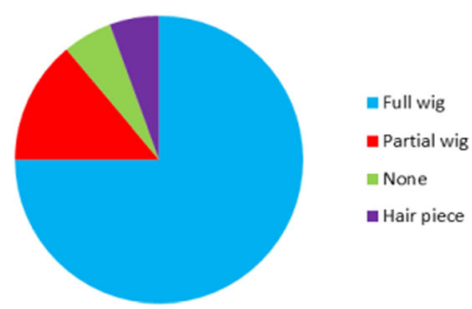

Is the current product you are using made from human hair or synthetic material?

Long term hair loss

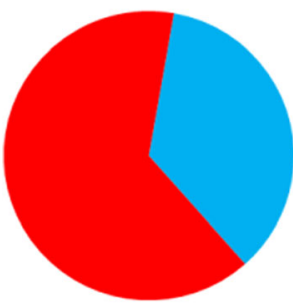

Short term hair loss

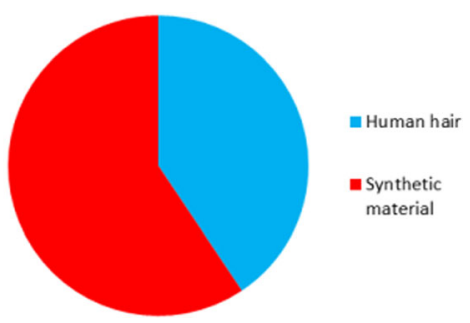

Fig. 7 FHPs used by those with hair loss 
look, avoiding attention and increasing confidence were key factors they associated with their FHP. However, many users reported issues with FHP quality and cost, noting that wigs were expensive to buy and replace, and when worn every day the quality of the wig did not last.

Users replaced their FHP on average 11.2 months for long term hair loss and 12.2 months for short term hair loss. Those with long term hair loss paid between $£ 100-£ 200$ for their FHP, while those with short term hair loss paid $£ 200-£ 300$. Only $5 \%$ of users with long term hair loss received their FHP from the NHS, in contrast to $62 \%$ of those with short term hair loss who had their FHP paid for by the NHS. Users were asked the condition of their FHP at the time of disposal - breakage and thinning of hair was the most common response and included frizzing of the hair ends (particularly for synthetic materials) and poor overall condition of the hair. Breakage, tearing and stretching of the cap were also widely reported.

\section{User survey - No hair loss}

It was impossible to source exact figures of the FHP market itself in the UK. However, figures from the hairdressing and beauty industry suggest the industry as a whole is growing. The National Hairdressers' Federation reported over 40,000 hairdressing, barbers and beauty salons in the UK for 2016, up 5000 from 2011 to 12 figures reported by HABIA [10]. The industry employs up to 270,000 people in the UK, making it the 5th most popular independent start-up business. Online reports estimate the UK hair extension industry to be worth between $£ 45-£ 60$ million, with some companies reporting a $70 \%$ growth over the last five years.

The user survey conducted as part of this study included those with no hair loss, with 67 respondents. Within this group, the type of FHPs used varied and included extensions, weaves and full wigs as the most popular products of choice as shown in Fig. 8. Motivations for wearing a FHP included dislike of own natural hair, a change in style and ease of maintenance. $56 \%$ reported their FHP to be made from human hair, while the remaining $44 \%$ currently used products made from synthetic fibres.

Users replaced their FHP on average every 3.2 months with the majority paying under $£ 100$ for their product. In many cases, users commented that this was due to a desire to change the style of their hair. Condition of the FHP at the time of disposal varied between those who updated due to the condition of the FHP (with the hair fibres becoming frizzy and adopting a tired appearance) and those who updated their FHP for a change of style (in which case the FHP was generally in good condition when disposed of).

What type of false hair product do you use?

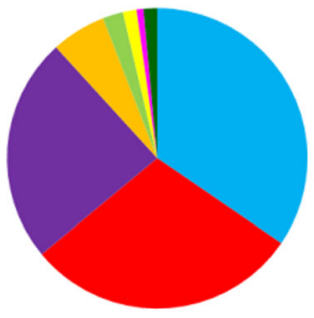

Is the current product you are using made from human hair or synthetic material?

m Extensions

weave

a Full wig

In Partial wig

weft

inoll on

mannequin

heads

araids

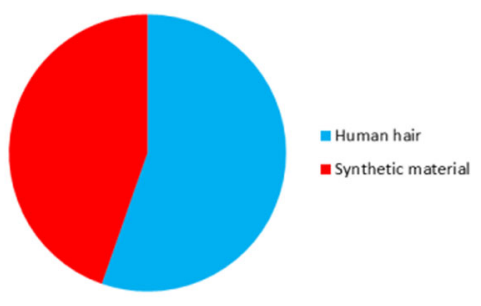

Fig. 8 FHPs used by those with no hair loss 


\section{User response to sourcing and manufacture of FHPs}

Table 2 summaries user responses to whether they would want to know whether materials used in their FHPs have been ethically sourced and the product sustainable manufactured. On average $70 \%$ of users across the three surveys wanted to know the materials had been ethically sourced, while $73 \%$ wanted to know the FHP had been sustainably manufactured. Figure 9 illustrates user importance placed on ethical sourcing, sustainable manufacture, both or neither - results were mixed between the three user groups, showing those with long term hair loss were more concerned with the sustainable manufacture of their FHP, while $59 \%$ of those with no hair loss felt both ethical sourcing and sustainable manufacture were equally important. When asked to expand on their responses, users reported: "I wish the donators to do so of their own free will and be compensated fairly" and "it is important no one is being unfairly treated or areas being misused". Those that did not want to know the sourcing and manufacturing origins of their FHP responded: "there are such limited options available, the look and feel of the wig has to be the top priority" and "all that matters is that I look normal and comfortable - where it comes from is quite irrelevant".

\section{Disposal of FHPs}

Informal interviews were set up with six wig banks in the UK to identify donations of used FHPs, restoration/reuse of these products and their disposal. Only wigs were donated - no other types of FHPs were reported. General findings indicated that wigs are often donated directly to the wig bank (either posted or delivered). The number of wigs donated varied between wig banks - from an average of 10 per month to 5-10 per year. One wig salon had announced a second hand wig event less than a month before the time of interview and had received $40+$ wigs from their customers over that timeframe, indicating that people were more likely to donate their FHP if they were aware of accessible facilities to do so.

With respect to the re-use of false hair products, only one example was identified in the UK where materials from used FHPs were reused in another, new product. In this case, those who wore quality human hair extensions are given the opportunity to donate their used extensions to charity, where they are made into wigs for those who had lost their hair through cancer treatment. The extensions used are made from human hair and are extremely high quality, which if maintained correctly, will remain for many months. Although only one example of this kind of material reuse was reported, it provides an example of the potential for the reuse of human hair, resulting in a quality product.

Table 2 User response to ethical sourcing and sustainable manufacture of FHPs

\begin{tabular}{lllll}
\hline & $\begin{array}{l}\text { Would you want to know that the } \\
\text { materials used in your FHP have } \\
\text { been ethically sourced? }\end{array}$ & & $\begin{array}{l}\text { Would you want to know that the materials } \\
\text { used in your FHP have been sustainably } \\
\text { manufactured? }\end{array}$ \\
\cline { 2 - 3 } & Yes & No & Yes & No \\
\hline Long term hair loss & $62 \%$ & $38 \%$ & $67 \%$ & $23 \%$ \\
Short term lair loss & $73 \%$ & $27 \%$ & $74 \%$ & $33 \%$ \\
No hair loss & $76 \%$ & $24 \%$ & & $26 \%$ \\
\hline
\end{tabular}


What is more important to you?
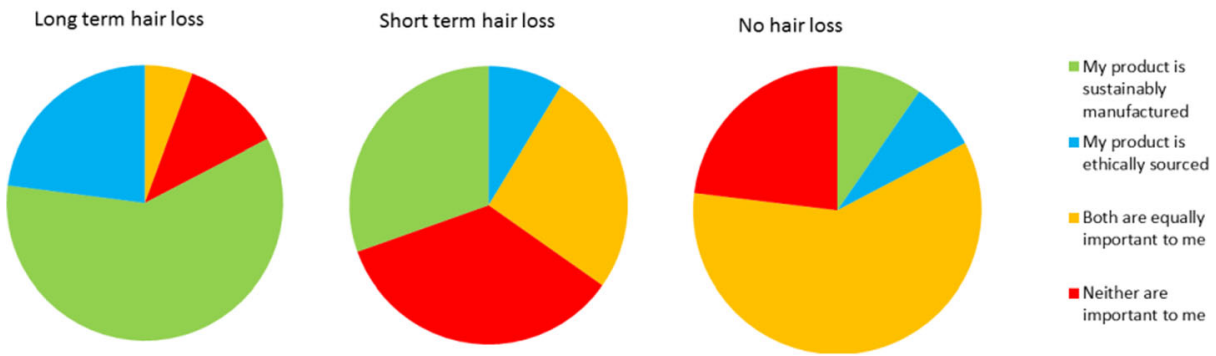

Fig. 9 Comparison of user importance on sourcing and manufacturing of FHPs

Most wigs donated to the wig banks were synthetic - wig banks that received human hair wigs tended to come from users who had received them themselves from charity, indicating that these higher quality human hair wigs were rarely bought by the users and had typically been used by those undergoing cancer treatment. Issues with the reuse of wigs included hygiene concerns and wigs often being personalised in terms of colour and style for the original recipient. The condition of the wigs received by the wig banks varied, with synthetic wigs typically reported as "frizzing" where the fibres had rubbed on the shoulders - in this case, the frizzed ends were cut before reuse. The reuse of wigs also varied between wig banks - some reused all donated wigs, not disposing of any as all donated wigs were in good condition. Others only reused wigs that were considered to be in good condition, while donating those of poorer quality to hairdressers for training purposes or to theatre groups. Where wigs could not be reused in anyway, they were disposed of as landfill waste. Wigs that were reused were typically cleaned (sterilised, washed, dried and treated) and restyled (cut to remove frayed ends).

Within the user survey, users were questioned on the condition of their FHP when it was disposed of. Responses from those with long and short term hair loss indicated that FHPs were in poor condition at the time of disposal with breakages in the hair most common, in addition to wear and tear of the cap. In contrast, responses from the user group with no hair loss reported that many FHPs were often in good condition and were replaced due to the user preferring a change in style. This agrees with finding where those with no hair loss reported their FHP lasting an average of 3.2 months, whereas FHPs used by those with long and short term hair loss lasted closer to a year on average. This indicates differing uses between user groups, where many users with long and short term hair loss use their product until it becomes worn out, while those with no hair loss update their FHP more frequently due to style changes.

The user survey asked each of the user groups how they currently disposed of their FHP, as shown in Fig. 10. It is clear the majority (72\% long term hair loss, 58\% short term hair loss, $96 \%$ no hair loss) currently dispose of their FHP by throwing it in the bin. However, when users were asked whether they would recycle their FHP if the facilities were available to do so, the majority (86\% long term hair loss, $89 \%$ short term hair loss, $67 \%$ no hair loss) responded that they would. The user surveys also asked FHP wearers whether they would wear a recycled, remanufactured or reconditioned FHP worn by either themselves or someone else, the results of which are summarised in Table 3. While the response to wearing someone else's recycled/reconditioned/remanufactured FHP was close to an even split for users with long term hair loss, a significant majority of those with short term hair loss and no hair loss would not wear a product previously worn by someone else. Quantitative responses from users indicated that hygiene issues associated with such a personal item were the main reason for user 
How do you currently dispose of your FHP?
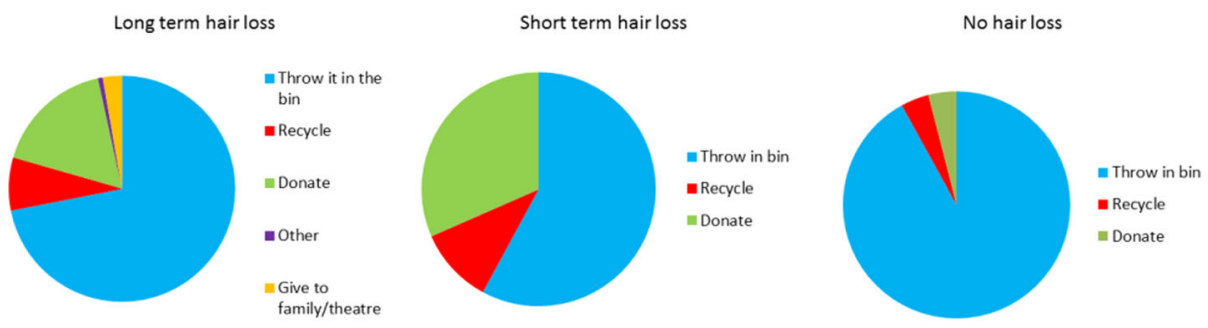

Would you recycle your FHP if the facilities were available to do so?
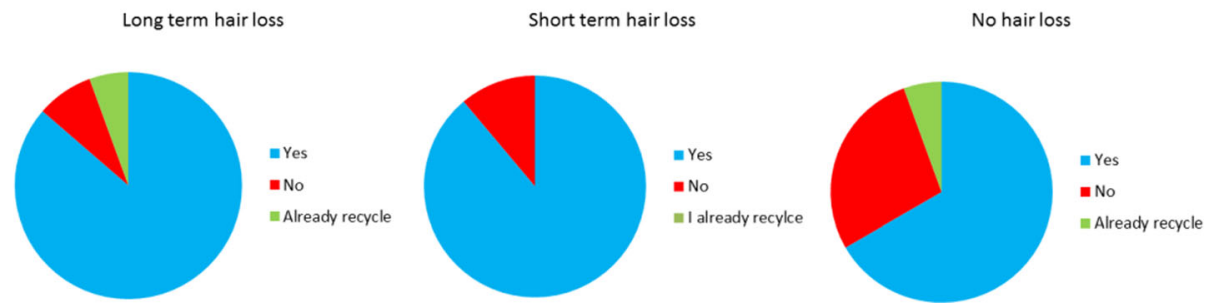

Fig. 10 Current and potential disposal of FHPs by all user groups

reluctance to buying a recycled/reconditioned/remanufactured product - "I don't know if another person would keep their wigs as clean" and "a wig is a personal thing so I wouldn't be comfortable wearing one that someone else had previously worn". Other responses simply indicated that users were not prepared to buy second hand goods - "I think it's related to social stigma around second hand personal items, and also knowledge of its previous use". The majority of respondents from all user groups indicated that they would wear a recycled/ reconditioned/remanufactured FHP that had previously been worn by themselves.

Manufacturers and suppliers were also questioned on how they disposed of waste materials. Human hair was identified as the most common waste material, with all respondents reporting they disposed of waste materials in landfill.

\section{Current FHP life cycle}

In response to the first research question - what is the current life cycle of FHPS - the first complete life cycle analysis of FHPs is illustrated in Fig. 11, based on results

Table 3 User response to use of recycled/restored FHPs

\begin{tabular}{|c|c|c|c|c|}
\hline & \multicolumn{2}{|c|}{$\begin{array}{l}\text { Would you buy a reconditioned/ recycled/ } \\
\text { remanufactured product previously owned } \\
\text { by someone else? }\end{array}$} & \multicolumn{2}{|c|}{$\begin{array}{l}\text { Would you buy a reconditioned/ recycled/ } \\
\text { remanufactured product previously owned } \\
\text { by yourself? }\end{array}$} \\
\hline & Yes & No & Yes & No \\
\hline Long term hair loss & $44 \%$ & $56 \%$ & $87 \%$ & $13 \%$ \\
\hline Short term lair loss & $22 \%$ & $78 \%$ & $58 \%$ & $42 \%$ \\
\hline No hair loss & $11 \%$ & $89 \%$ & $54 \%$ & $46 \%$ \\
\hline
\end{tabular}




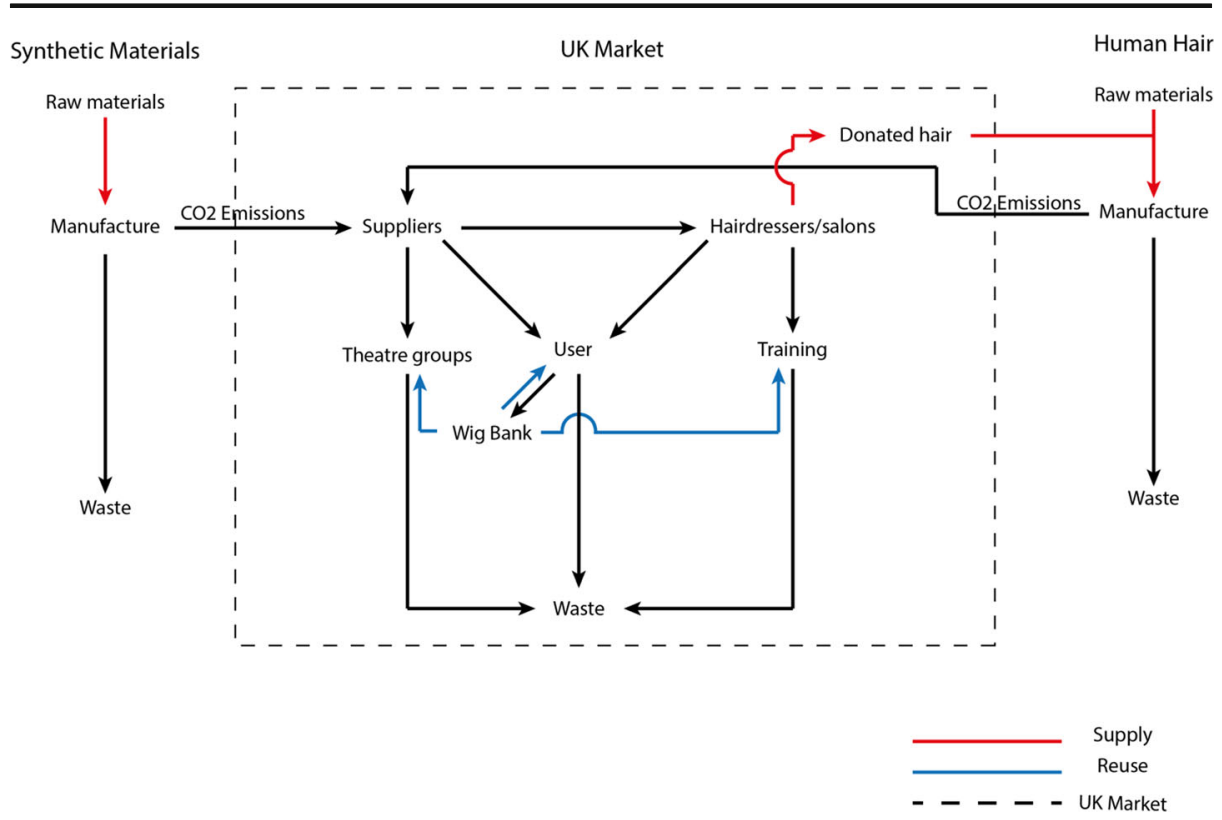

Fig. 11 Current life cycle of FHPs

detailed in this section. The life cycle is predominantly linear - little evidence was found of current recycling and reuse of materials. The life cycle illustrates the global supply chain of materials and manufacture of FHPs, before the products are sold, used and disposed of within the UK market. Although not significant within the size of the false hair market, instances of product reuse are noted where users donate used FHPs to wig banks. These FHPs are either reused by the user, theatre groups or hairdresser training. Products that are not suitable for reuse are disposed of.

\section{Discussion}

The following results were found from the data presented here and are discussed within this section:

1. The false hair industry is a growing, global industry.

2. There is a complex global supply chain to provide the UK with FHPs.

3. The current life cycle of FHPs is short and linear from cradle-to-grave.

4. There is no significant process currently in place to capture FHP waste for reuse or recycle.

\section{Growth of the global false hair industry}

The false hair industry, both in the UK and internationally, is expected to grow as the demand and fashion for longer, thicker hair and consumer desire to change appearance and follow trends continues. This will continue to place demands on the supply of FHPs and subsequently 
on the supply of human hair and production of synthetic fibres. It is acknowledged within the literature that human hair results in a better product due to its quality and durability [27]. However, it is more expensive to buy than its synthetic counterpart, with this likely to remain so as human hair is evidently becoming harder to source [20]. While the synthetic materials used in FHPs are cheaper and more readily available, it is important to consider alternatives to such materials to reduce the environmental impact of these disposable products.

The exact size of the FHP industry remains unknown. The lack of data received from the NHS highlights that little is known about the medical FHP market with findings from this research indicating that the medical hair loss market is likely to be significantly larger than reported - only $5 \%$ of respondents from the long term hair loss survey and $62 \%$ of those with short term hair loss reported receiving their FHP from the NHS. This presents a large number of users who are not recorded by the NHS.

For many who have still have their own hair, FHPs offer the possibility of enhancing or protecting what they have, or to change style completely. For those who have lost their hair, FHPs offer the user the chance to blend in, avoid attention and reclaim part of their original identity from before the hair loss. For this group with medical hair loss, it is vital that FHPs remain available and affordable, with responses within the user survey indicating cost and quality are often not met with existing products. While trends and social perceptions lean towards long, thick hair, the demand for FHPs (from both the cosmetic and medical market) will continue. To reduce the demand on raw materials and ultimately the cost to the user, it is recommended that FHPs are reused and recycled where possible.

\section{Global supply chain of FHPs}

The supply chain for FHPs is a global one, with human hair originating from countries including India, China, Brazil and Eastern Europe, while synthetic fibres are produced in China, Japan and Korea. Manufacturing of both human hair and synthetic fibres to create FHPs occurs in countries including China, Myanmar and Bangladesh, before distribution to suppliers and users, predominantly in Western countries. The creation of a circular economy and the reuse of waste materials domestically will help to reduce both the global demand on raw materials by keeping material sourcing local and the environmental impact of moving materials through the global supply chain. Reuse of FHP materials domestically will also create job opportunities in countries where the use and disposal of FHPs is high. While this research focused specifically on the UK, the potential to create a domestic supply chain through the reuse of FHPs is applicable on a global scale.

\section{Current life cycle of FHPs}

With decreasing supplies of human hair and the environmental impact of synthetic fibres, there is a need to consider other material sources for FHPs. The user survey found that those with no hair loss updated their FHP more regularly than those with long and short term hair loss - on average every 3.2 months compared to 11.2 and 12.2 months. The findings from the survey indicated that users with no hair loss updated their FHP due to a desire for a style change, while those with hair loss updated their FHP once it had become worn. These results find some differences with findings by Saed, et al. [17] who indicated that inexpensive, synthetic wigs would last 3-6 months if worn every day. That same study also proposes that high quality human hair wigs could last 3-4 years - within this research, the user surveys conducted in this 
research found that $92 \%$ of respondents reported their FHP lasting less than two years, with $79 \%$ reporting that their FHP lasted less than a year. While the results from this study include both human hair and synthetic fibre wigs, it is concluded that the majority of FHPs need to be replaced on an annual basis.

Many of those with no hair loss reported that their FHP was still in good condition at time of disposal and was updated due to change in style. This indicates that there is scope for reuse of these products to minimise waste and finds agreement with recommendations made in previous literature [9] that there is a need buy-back schemes or equivalent to encourage the recycling of human hair materials. In addition, when asked for detail on the condition of the FHP at time of disposal, many users from all user groups reported specific areas of deterioration (i.e. the cap, fitment, hair, hair ends, etc.) indicating that some component parts of the FHP could still be in good condition at time of disposal. This was also reflected in the findings from interviews with the wig banks, which indicate that donated wigs are typically in a condition where they can be reused with minimal restoration work. It is therefore concluded that unused wigs in good condition are donated and the decision to dispose of worn-out FHPs lies predominantly with the user.

\section{Opportunities to capture waste within current FHP life cycle}

Within the identified life cycle of FHPs, several opportunities for capturing waste have been identified, as illustrated in Fig. 12. These opportunities present solutions to the second and third research questions - how can the demand on natural hair resources be reduced, and how can the environmental impact of synthetic FHP fibres be minimised?

The current FHP life cycle is largely linear from cradle to grave, with some occasional instances of product reuse reported by the wig banks. There is therefore an opportunity to facilitate waste collection towards the end of the product life cycle to open up opportunities for recycle, recondition and remanufacture of FHPs. Gupta [9] outlines opportunities for the reuse
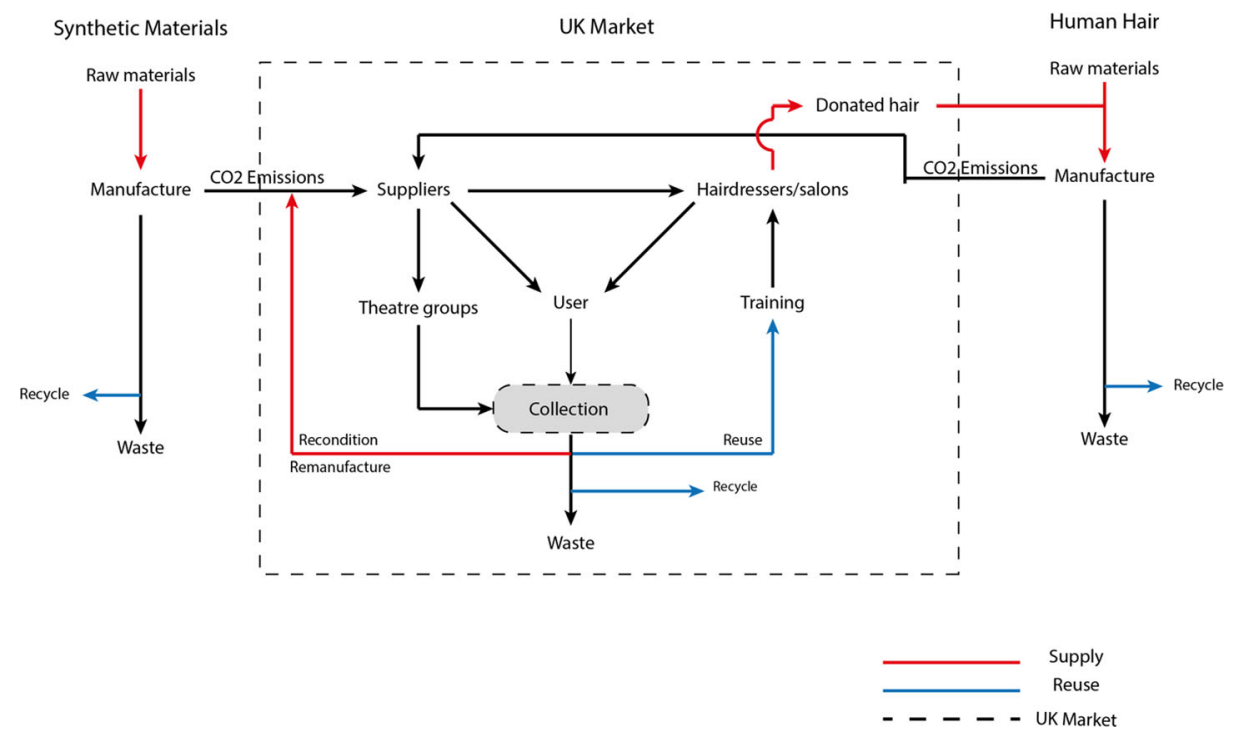

Fig. 12 Opportunities to reduce waste within current FHP life cycle 
of human hair, as discussed earlier in this paper, indicating that human hair not fit for reuse can be collected for alternative purposes. However, in response to the need to reduce the demand on raw materials (particularly human hair), this research indicates that there is also a need to consider the reconditioning and remanufacture of FHPs, taking into account user concerns of hygiene associated with such products. Collecting materials and remanufacturing in the UK would also reduce the need for importing raw materials and new products, therefore reducing carbon emissions through global shipping.

It is also important to consider factors that will aid the reconditioning/remanufacturing process. Currently FHPs are made from a range of different materials, from different hair fibres, mechanical attachments and adhesives. Work has already been conducted into creating artificial hair fibres using biomass materials [27], which would both help to reduce the environmental impact of FHPs and their waste, in addition to reducing demand on other raw materials. It is also recommended that there is standardisation it the types of materials used in FHPs to facilitate the reconditioning/remanufacturing process.

User response to the use of recycled, reconditioned and remanufactured FHPs are important and must be considered if these approaches are to be adopted. The majority of all user groups indicated they would recycle their FHP is the facilities to do so were available. It is therefore important that such facilities are in place in order to capture waste products. The results indicated that the majority of users would not reuse a product that had previously been owned by someone else, but would if that product had been previously owned by themselves. Reasons for this cited hygiene issues and that FHPs are highly personal products, which finds agreement with Abbey, et al. [1] who found that many users believe a product can become dirty or contaminated through prior ownership. It is noted that human hair used in FHPs is already sourced from another person (the original donator of the hair) making these findings interesting as users are only reluctant to reuse the FHP itself, while readily utilise a "new" FHP sourced from another person. User perceptions towards the recycling, reconditioning and remanufacture of these products must be considered in the collection, reuse and resale of such products to ensure efforts to improve the sustainability of this industry are successful. The majority of all user groups indicated they wanted to know their FHPs were ethically sourced and sustainably manufactured. Transparency in the reuse of FHP materials will be important in gaining user confidence in such products, in addition to overcoming user perceptions of remanufactured products as "second hand goods".

The false hair industry is currently a "throwaway" one, where products have a short life span and are considered as disposable. Integrating waste back into the production cycle, will reduce costs of waste disposal and volume of landfill waste. This research recommends that there is a need for the false hair industry to progress towards a circular economy, where products are designed and manufactured with the intention of recycle, recondition and remanufacture. This will extend the existing lifecycle of these products, which is currently less than 12 months and will reduce the demand for human hair. The reduction in demand for raw materials and potential for a domestic remanufacturing industry would significantly reduce costs, which would be passed on to the customer.

\section{Conclusions}

With the continuing high demand for FHPs, there is an increased strain on the global supply of human hair and environmental concerns over the disposal of synthetic materials. This paper 
reports on the research conducted to investigate the current life cycle of such FHPs and identify opportunities to sustainably capture waste within it. A combination of desk research, user and manufacturer surveys, NHS study and wig bank interviews were conducted, to capture the current life cycle of FHPs. The research shows a complex global supply chain, for which there is a lack of data available. This research contributes the current life cycle of FHPs, which is clearly evidenced within this study as cradle-to-grave, with little reuse of materials and no significant processes in place to capture waste. Further contributions of this research include identification of opportunities to sustainably capture waste within this life cycle and create a closed loop supply chain within the false hair industry. This includes capture of waste products direct from users to utilise materials in the reconditioning/remanufacture of new products, in addition to the recycling of materials for alternative purposes. This will help to reduce strain on the demand for raw materials and reduce the amount of waste generated within the industry. To improve the ease of remanufacturing within the process, it is also recommended that the materials used for FHPs are standardised.

This work has the potential to have a major impact on both the future FHP manufacturing industry by moving sourcing and remanufacture of product domestically. As the first research to identify the current lifecycle of FHPs, opportunities to capture waste will reduce the environmental impact of this global industry through decreasing the demand on both human hair and synthetic fibres, reducing the carbon footprint of the global supply chain by identifying opportunities to remanufacture FHPs domestically and reducing the volume of FHPs sent to landfill. This research will also have a positive impact on end use experience by identifying current user needs and their perceptions of the reuse of FHPs, which are recommended to be accommodated with the creation of a FHP circular economy.

With societal trends continuing to encourage the use of FHPs and the medical demand for FHPs set to increase, it is vital that opportunities to extend the life cycle of these products are considered. Future work that has been identified includes research into the synthetic materials used in FHPs to reduce their environmental impact. Potential reuses for both synthetic fibres and human hair must be also explored and alternative materials developed. Mechanisms to capture the waste opportunities explored within this research must also be explored further to create a sustainable circular economy within the false hair industry.

Acknowledgments This research was funded by the Scottish Institute of Remanufacture (SIR).

The authors would also like to thank the following organisations for distribution of the user survey: Alopecia UK, Scottish Alopecia Support Group, LA Hair Solutions, Parrucche Wig and Hair Boutique, Maggie's.

Open Access This article is distributed under the terms of the Creative Commons Attribution 4.0 International License (http://creativecommons.org/licenses/by/4.0/), which permits unrestricted use, distribution, and reproduction in any medium, provided you give appropriate credit to the original author(s) and the source, provide a link to the Creative Commons license, and indicate if changes were made.

Publisher's note Springer Nature remains neutral with regard to jurisdictional claims in published maps and institutional affiliations.

\section{References}

1. Abbey JD, Meloy MG, Guide DR, Atalay S (2015) Remanufactured products in closed-loop supply chains for consumer goods. Prod Oper Manag 24(3):488-503 
2. Aguh, C. and Okoye, G. (2017). Fundementals of ethnic hair: the dermatologist's perspective. Springer International Publishing Switzerland

3. Banka N, Bunagan MJK, Dubrule Y, Shapiro J (2012) Wigs and hairpieces: evaluating dermatologic issues. Dermatol Ther 25:260-266

4. Braun D (2002) Recycling of PVC. Prog Polym Sci 27(10):2171-2195

5. Crawford CB, Quinn B (2017) Microplastic pollutants. Elsevier Inc., Oxford

6. Donovan JCH, Shapiro RL, Shapiro P, Zupan M, Pierre-Lois M, Hordinsky MK (2012) A review of scalp camouflaging agents and prostheses for individuals with hair loss. Dermatol Online J 18(8)

7. Eichhorn SJ, Hearle JWS, Jaffe M, Kikutani T (2009) Handbook of textile fibre structure: volume 1 fundamentals and manufactured polymer fibres. Woodhead Publishing Limited, Cambridge

8. Ghalachyan A, MacGilivray MS (2016) Designing headwear for women with chemotherapy-induced hair loss. International Journal of Fashion Design, Technology and Education 9(3):222-232

9. Gupta A (2014) Human hair "waste" and its utilisation: gaps and possibilities. Waste Manag 2014:1-17

10. Hair and Beauty Industry Authority (2017). Accessed 10 September 2017 from www.habia.org/industryoverview/\#general-stats?BImore

11. Hargreaves, K., Preston, I., White, V., Thumin, J. (2013). The distribution of household $\mathrm{CO}_{2}$ emissions in Great Britain. JRF program paper: climate change and social justice. Centre for sustainable energy

12. Ijomah, W. L., Childe, S., McMahon, C. (2004) Remanufacturing: A key strategy for sustainable development. Proceedings of the 3rd international conference on design and manufacture for sustainable development. Cambridge University Press

13. Koelmanns AA (2014) ET\&C Perspectives. Environ Toxicol Chem 33:5-10

14. Lacy P, Rutqvisy J (2015) Waste to wealth: the circular economy advantage. Palgrave MacMillan, New York

15. Ladizinski B, Nutan FN, Ganta N, Norton SA (2013) Tonsuring in India and the global trade in human hair. JAMA Dermatol 149(9):1021-1022

16. Montgomery K, White C, Thompson A (2017) A mixed methods survey of social anxiety, anxiety, depression and wig use in alopecia. Br Med J 7

17. Saed S, Ibrahum O, Bergfeld WF (2016) Hair camouflage: a comprehensive review. Int J Women's Dermatol 2:122-127

18. Savaskan RB, Bhattacharya S, Van WLN (2004) Closed-loop supply chain models with product remanufacturing. Manag Sci 50:239-252

19. Scottish Institute for Remanufacturing (2017). What is remanufacturing? Accessed 29 October 2017 from http://www.scot-reman.ac.uk/about-remanufacturing/what-is-remanufacturing/

20. Tarlo E (2016) Entanglement: the secret lives of hair. OneWorld Publications, London

21. The Observatory of Economic Complexity (2017). Human hair. Accessed 14 December 2017 from https://atlas.media.mit.edu/en/profile/hs92/0501/

22. The Scottish Government (2011). Health and healthcare improvement directorate. Edinburgh

23. Thomas DR (2006) A general inductive approach for analysing qualitative evaluation data. Am J Eval 27: 237-246

24. Thomson RC, Moore CJ, vom Saal FS, Swan SH (2009). Plastics, the environment and human health: current concensus and future trends. Philos Trans R Soc Lond B Biol Sci 364:2153-2166

25. Wiggins S, Moore-Millar K, Thomson A (2014) Can you pull it off? Appearance modifying behaviours adopted by wig users with alopecia in social interactions. Body Image 11(2):156-166

26. World Shipping Council (2017). Carbon Emissions. Accessed 29 October 2017 from http://www. worldshipping.org/industry-issues/environment/air-emissions/carbon-emissions

27. Yang L, Guo J, Zhang S, Gong Y (2017) Preparation and characterisation of novel super-artificial hair fibre based on biomass materials. Int J Biol Macromol 99:166-172 